\title{
The effects of a caffeine-containing beverage on neuromuscular performance during a multi-joint, lower body power exercise
}

Meghan McCann, Amanda Wright, Stephen Siegle, Jenna Veldhuizen, Stephanie Wojton, Kelsey Jacobs, Eric Kuklinski, Tyler Krings, Elizabeth Scheckel, Carly Homan, Emily Kammerer, Dawn Anderson, Lonnie Lowery ${ }^{*}$

From International Society of Sports Nutrition: 9th Annual ISSN Conference and Expo

Clearwater, FL, USA. 22-23 June 2012

\section{Background}

Current research has shown varied results when comparing the effects of caffeinated beverages on explosive exercise movements. We hypothesized that lower body muscular explosiveness would be significantly increased $(\mathrm{p}<0.05)$ after Redline ${ }^{\circledR}$ energy drink ingestion versus a similar placebo (PLB) drink in recreationally active subjects $(n=16)$.

\section{Methods}

After a day of dietary control and caffeine abstinence, otherwise-fasted participants performed four separate, strict squat jumps (SJ) under both conditions $48-96$ hours apart. The variables measured included peak power (POW), peak force (FOR), peak velocity (VEL), maximal displacement (DSP), and maximal rate of force development (RFD) in the SJ for both Redline ${ }^{\mathbb{R}}$ energy drink and PLB trials.

\section{Results}

These preliminary data illustrated a significant increase in peak velocity in the Redline ${ }^{\circledR}$ energy drink condition versus PLB (Redline ${ }^{\circledR} 2.35 \pm 0.36 \mathrm{~m} / \mathrm{s}$ vs. PLB $2.29 \pm 0.34 \mathrm{~m} / \mathrm{s}$ $[p=0.033])$. All other variables were regarded as nonsignificant.

\section{Conclusion}

Our early findings only partially support our hypothesis because all but one variable was unaffected during the squat jump. Future research should focus on potential

\footnotetext{
* Correspondence: lowerylm@mountunion.edu

Department of Health, Exercise and Rehabilitative Sciences, Winona State
} University, Winona, MN 55987, USA

(c) 2012 McCann et al; licensee BioMed Central Ltd. This is an Open Access article distributed under the terms of the Creative Commons Attribution License (http://creativecommons.org/licenses/by/2.0), which permits unrestricted use, distribution, and reproduction in any medium, provided the original work is properly cited. differences between upper- and lower-body power exercises as they respond to caffeine-related interventions.

Published: 19 November 2012

doi:10.1186/1550-2783-9-S1-P22

Cite this article as: McCann et al:: The effects of a caffeine-containing beverage on neuromuscular performance during a multi-joint, lower body power exercise. Journal of the International Society of Sports Nutrition 2012 9(Suppl 1):P22. and take full advantage of:

- Convenient online submission

- Thorough peer review

- No space constraints or color figure charges

- Immediate publication on acceptance

- Inclusion in PubMed, CAS, Scopus and Google Scholar

- Research which is freely available for redistribution 